KOLOM ILMIAH

Social Humaniora

\title{
EFEKTIVITAS PROGRAM ADOLESCENCE CHARACTER BUILDING (ACB) TERHADAP PENANAMAN KARAKTER REMAJA DI KABUPATEN SUMBAWA
}

\author{
Yossy Dwi Erliana1, Roni Hartono \\ ${ }^{12}$ Program Studi Psikologi, Fakultas Psikologi, Universitas Teknologi Sumbawa. \\ Email: yossyerliana23@gmail.com,roni.hartono@uts.ac.id
}

\begin{abstract}
Diterima:

Januari 2019

Februari 2019

Keywords:

$A C B$, adolescent, character

Adolescence is an important stage in human development. This study aims to determine the effectiveness of the Adolescence Character Building (ACB) program in order to build of adolescents characters in Sumbawa Regency. The population is high school students in the capital of Sumbawa Regency by using samples of students of SMAN 2 Sumbawa Besar. The program was conducted for three days on July $16^{\text {th }}$, $18^{\text {th }}$ and $19^{\text {th }}$. The independent variable is ACB program, while the dependent variable is character understanding in adolescent. The participants are given a pretest sheet. Program was delivered by instruction (lecture), discussion, simulation, and game. During learning the particiants get eight ACB modules, namely (1) Introduction of Self; (2) Learning Styles; (3) Goal, Mission, and Time Management; (4) Reactive and Proactive; (5) Conflict Management; (6) Assertive and Critical Thinking; (7) Empathy and Respect for Others; and (8) Leadership. After the program is completed the participants are given post-test sheet. The effectiveness of the program was analyzed using the Wilcoxon Signed-Ranks test to examine differences student's understanding about the value of character between before and after program intervention. The results of this study indicate that there is influence of ACB program implementation on the participants. The post-test score is higher than the pre-test score. The effectiveness of the program during the study may be due to internal and external factors. Internal factors such as an understanding of some participants to the values of character. External factors include an appropriate and fun methods, relevant material and professional instructor.
\end{abstract}

\section{PENDAHULUAN}

\section{Latar Belakang}

Maraknya peristiwa tawuran pelajar, sex bebas, penyalahgunaan narkoba, bunuh diri di kalangan remaja, praktek-praktek curang dalam ujian dan sebagainya merupakan sinyal terjadinya pergeseran nilai di kalangan generasi muda kita. Gejala terpuruknya benteng moral dan karakter positif di kalangan remaja juga tampak di Kabupaten Sumbawa. Beberapa contoh kasus yang terjadi diantaranya beredarnya gambar-gambar pornografi di perangkat smartphone peserta didik, tawuran antar genk remaja, maraknya kasus MBA (married by accident) remaja putri dan kejadian lainnya.

Pembangunan pendidikan di semua tingkat pendidikan sebenarnya sudah dilakukan. Pengembangan selama ini cenderung fokus pada peningkatan akses dan mutu pendidikan. Peningkatan akses pendidikan berupa pembangunan gedung-gedung sekolah dan sarana prasarana penunjang aktifitas belajar mengajar. Peningkatan mutu pendidikan pun dilakukan secara massif berupa pengadaan media pembelajaran seperti buku dan laboratorium dan upgrading kapasitas pendidik dan tenaga kependidikan. Semua itu dimungkinkan karena dukungan pembiayaan sektor pendidikan di negara ini cukup besar sesuai amanat konstitusi.

Namun kenapa kejadian-kejadian yang mencoreng dunia pendidikan masih marak terjadi? Ternyata pembangunan pendidikan itu tidak melulu urusan pembangunan infrastruktur, seperti gedung sekolah, laboratorium dan pengadaan buku ajar. Aspek yang selama ini kurang disentuh adalah pembangunan mental dan karakter peserta didik. Kita berpacu mengembangkan metode pembelajaran mutakhir yang mampu mencetak siswa dengan capaian kognisi maksimal, tapi kurang menanamkan budi pekerti, etika, moral dan karakterkarakter terpuji lainnya kepada siswa.

Temuan atau kasus di atas menunjukkan betapa terpuruknya dan lemahnya karakter bangsa ini, terutama di dunia pendidikan, penanaman nilai-nilai positif yang harusnya dilakukan oleh para guru atau pengajar justru dirusak oleh mereka dengan melakukan kecurangankecurangan. Sekolah sebagai salah satu sarana pendidikan memiliki fungsi bukan hanya menciptakan para peserta didiknya yang cerdas tapi juga berakhlak, kreatif, 


\section{JURNAL TAMBORA}

Vol. 3 No. 1 Februari 2019

bertanggung jawab, inovatif dan mampu menumbuhkan kepenasaranan intelektual pada peserta didik atau menumbuhkan rasa ingin tahu dan semangat pembelajar.

Kenakalan remaja memiliki sifat psikis, interpersonal, antarpersonal, dan kultural sebab perilaku kenakalan selalu berlangsung dalam konteks sosio-kultural (Kartono, 2010 dalam Sriyanto et al., 2014). Individu menjadi faktor utama dalam memilih dan menentukan eksistensi dirinya dalam membentuk karakter agresif, asertif atau pasif. Pendidikan menjadi sarana yang efektif untuk mengembangkan kemampuan dan membangun karakter peserta didik.

Berangkat dari keprihatinan dan tanggung jawab sebagai pendidik, penulis menggagas program Adolescence Character Building (ACB) sebagai upaya penanaman pendidikan karakter di kalangan remaja. Melalui pengenalan dan pembelajaran tentang materi pengenalan diri; gaya belajar; goal, misi, dan manajemen waktu; reaktif dan proaktif; manajemen konflik; asertif dan berpikir kritis; empati dan menghargai orang lain; dan kepemimpinan (leadership) diharapkan tumbuh karakter siswa yang tangguh, memiliki etos kerja, disiplin, bertanggung jawab, toleran, berakhlak baik, kreatif dan inovatif.

Penelitian ini bertujuan untuk memberikan pemahaman peserta didik terhadap diri dan potensi yang dimilikinya sehingga mampu mencari cara pengembangannya, meningkatkan kemampuan peserta didik (soft skill) untuk mengolah hati, pikir, rasa dan raga sehingga mampu menjadi desicion maker dan problem solver, memberikan pemahaman sampai pada internalisasi nilai-nilai positif yang membentuk karakter pada diri remaja.

\section{Sasaran/Peserta}

Sasaran/peserta penelitian ini adalah para siswa sekolah menengah pertama dan atas agar mampu memanfaatkan saat-saat terbaik dalam hidupnya secara baik dan bertanggung jawab. Program ACB sangat baik jika disinergikan dengan pelaksanaan kegiatan orientasi sekolah.

\section{Keluaran (Output)}

Keluaran (output) dari penelitian ini adalah (1) Dihasilkannya peserta didik dan lulusan yang kreatif, inovatif, cerdas dan berkarakter kuat, sehingga mampu menyelesaikan permasalahan dengan cara-cara yang positif dan cerdas; dan (2) Dihasilkannya rekomendasi kepada pemerintah Kabupaten Sumbawa melalui SKPD yang mengelola urusan pendidikan dan sekolah-sekolah menengah mengenai program yang dapat digunakan untuk pembentukan karakter dan dapat diinternalisasikan sebagai kurikulum tetap tahunan.

\section{LANDASAN TEORI}

\section{Perkembangan dan Psikologi Remaja}

Perkembangan manusia merupakan suatu proses sepanjang kehidupan dari pertumbuhan dan perubahan fisik, perilaku, kognitif dan emosional. Sepanjang proses ini, tiap individu mengembangkan sikap dan nilai yang
JURNAL TAMBORA

ISSN 2527-970X | e-ISSN 2621-542X

mengarahkan pilihan, hubungan dan pengertian (understanding).

Salah satu periode dalam perkembangan adalah masa remaja. Kata remaja (adolescence) berasal dari bahasa Latin adolescere yang artinya tumbuh ke arah kematangan. Istilah kematangan meliputi kematangan fisik maupun sosial-psikologis. Menurut WHO (Herlina, 2013), remaja adalah suatu masa dimana:

1. Individu berkembang dari saat pertama kali ia menunjukkan tanda-tanda seksual seksual sekundernya sampai mencapai kematangan seksual (kiteria biologis).

2. Individu mengalami perkembangan psikologis dan pola identifikasi dari kanak-kanak menjadi dewasa (kriteria sosial-psikologis).

3. Terjadi peralihan dari ketergantungan sosialekonomi yang penuh kepada keadaan yang relatif lebih mandiri (kriteria sosial-ekonomi).

Masa remaja dibagi dua bagian, yaitu periode remaja awal (early adolescence) kisaran umur 13-17 tahun dan periode remaja akhir kisaran umur 17-18 tahun. Pada periode remaja akhir, individu sudah mencapai transisi perkembangan yang lebih mendekati masa dewasa.

Ciri-ciri yang menonjol yang pada usia-usia ini terutama terlihat pada perilaku sosialnya. Dalam masamasa ini teman sebaya mempunyai arti yang amat penting. Mereka ikut dalam kelompok, klik atau genk sebaya (peer group) yang perilaku dan nilai kolektifnya sangat mempengaruhi perilaku serta nilai-nilai individu yang menjadi anggotanya. Inilah proses individu membentuk pola perilaku dan nilai-nilai baru yang pada gilirannya bisa menggantikan nilai dan perilaku yang dipelajarinya di rumah.

Remaja adalah seorang idealis, ia memandang dunianya seperti apa yang dia inginkan, bukan sebagaimana adanya. Ia suka mimpi-mimpi yang sering membuatnya marah, cepat tersinggung atau frustrasi. Selain itu oleh keluarga dan masyarakat ia dianggap sudah dewasa sehingga diberi tanggung jawab layaknya orang yang sudah dewasa. Ia mulai memperhatikan prestasi dalam segala hal karena ini memberinya nilai tambah untuk kedudukan sosialnya diantara teman sebaya maupun orang dewasa.

Periode remaja adalah periode pemantapan identitas. Pengertiannya akan 'siapa aku' yang dipengaruhi oleh pandangan orang-orang di sekitarnya serta pengalamanpengalaman pribadinya akan menentukan pola perilakunya sebagai orang dewasa.

Pemantapan identitas diri ini tidak selalu mulus, tetapi sering melalui proses yang panjang dan bergejolak. Oleh karena itu banyak ahli menamakan periode ini sebagai masa-masa storm and stress atau masa up and down. Masa yang penuh dengan emosi yang muncul karena adanya pertentangan nilai-nilai.

Menurut Berk (2003) dalam Herlina (2013), pada masa remaja, perkembangan kognitif sudah mencapai tahap puncak. Beberapa ciri perkembangan kognitif pada masa ini antara lain: 


\section{JURNAL TAMBORA}

Vol. 3 No. 1 Februari 2019

1. Mampu menalar secara abstrak melalui penalaran deduktif hipotetis dan berpikir secara proposisional. Penalaran deduktif hipotetis yaitu kemampuan penyelesaian suatu permasalahan yang dimulai dari 'teori umum' dari faktor-faktor yang mungkin mempengaruhi dan membangun hipotesis (prediksi) yang mungkin terjadi. Berpikir proposisional memungkinkan remaja dapat mengevaluasi logika proposisi tanpa merujuk kepada keadaan dunia nyata.

2. Memperlihatkan distorsi kognitif, yaitu pendengar imajiner dan dongeng pribadi (personal fable).

Menurut Zeman (2001) dalam Herlina (2013), beberapa ciri perkembangan emosional pada remaja adalah:

1. Memiliki kemampuan mengembangkan hubungan jangka panjang, sehat dan berbalasan.

2. Memahami perasaan sendiri dan memiliki kemampuan untuk menganalisis mengapa mereka memiliki perasaan dengan cara tertentu.

3. Mulai mengurangi nilai tentang penampilan dan lebih menekankan pada nilai kepribadian.

4. Memiliki kemampuan mengelola emosi melalui kemampuan berdiskusi dan meningkatnya sensitivitas remaja.

Menurut Oswalt (2010), beberapa ciri perkembangan sosial pada masa remaja sebagai berikut:

1. Keterlibatan dalam hubungan sosial lebih mendalam dan secara emosional lebih intim dibandingkan masa kanak-kanak.

2. Jaringan sosial meluas baik jumlah orang maupun jenis hubungan sosial.

3. Terjadi krisis identitas karena transisi tahap perkembangan yang harus diselesaikan dengan baik.

\section{METODOLOGI}

\section{Identifikasi Variabel Penelitian}

Variabel bebas pada penelitian adalah Program Adolescence Character Building (ACB), yang secara teoritis didefinisikan sebagai program yang dimaksudkan untuk mengarahkan peserta didik yang dalam perkembangannya termasuk masa remaja yang sangat rentan akan badai dan stress (Storm and Stress), sehingga mereka mampu mengolah hati mereka, mengolah pikiran mereka, mengolah raga mereka dan mengolah rasa mereka untuk mampu menjadi desicion maker dan problem solver sebagai bekal menghadapi kehidupannya yang sedang berlangsung dan akan datang.

Variabel terikat pada penelitian ini adalah penanaman karakter pada remaja, yang secara teoritis didefinisikan sebagai pembentukan nilai-nilai positif pada diri remaja (peserta didik) sebagai pembentuk karakter yang berasal dari olah hati, olah pikir, olah rasa dan olah raga.

\section{Waktu dan Tempat Penelitian}

Program ini dilaksanakan di sekolah menengah atas yang terpilih di Kota Sumbawa Besar, Kabupaten Sumbawa pada bulan Juli 2017 yaitu di SMAN 2
JURNAL TAMBORA

ISSN 2527-970X | e-ISSN 2621-542X

Sumbawa Besar yang pelaksanaannya bertepatan dengan pelaksanaan program MOS di sekolah yang bersangkutan.

\section{Sumber Data}

Jenis data yang dikumpulkan dari subyek penelitian ini meliputi data primer dan sekunder. Data primer diperoleh terutama dari subyek penelitian. Data sekunder diperoleh dari berbagai dokumen tertulis, seperti laporan penelitian sebelumnya, data dari berbagai instansi terkait dan referensi ilmiah lainnya. Subyek penelitian ini adalah para siswa yang terpilih mengikuti program ACB di SMAN 2 Sumbawa Besar, Kabupaten Sumbawa.

\section{Metode Pengumpulan Data}

Metode pengumpulan data adalah observasi dan penggunaan alat tes. Observasi adalah upaya mengamati dan mendokumentasikan hal-hal yang terjadi selama tindakan berlangsung. Pada saat dilakukan tindakan, secara bersamaan juga dilakukan pengamatan tentang segala sesuatu yang terjadi selama proses pembelajaran berlangsung (Suryana, 2010). Observasi dilakukan di dalam kelas selama pelaksanaan program ACB. Observasi yang dilakukan oleh observer adalah observasi dimana keberadaan observer disadari oleh subyek, namun subyek tidak mengetahui tujuan atau maksud dari kehadiran observer (Sugiyono, 2012).

Alat tes yang digunakan berupa sejumlah pertanyaan yang diberikan sebelum pemberian materi (pretest) dan setelah pemberian materi (posttest).

\section{Prosedur Pelaksanaan Program ACB}

Pemberian materi ACB mengacu pada delapan modul yang telah disiapkan, yaitu (1) Pengenalan Diri; (2) Gaya Belajar; (3) Goal, Misi, dan Manajemen Waktu; (4) Reaktif dan Proaktif; (5) Manajemen Konflik; (6) Asertif dan Berpikir Kritis; (7) Empati dan Menghargai Orang Lain; dan (8) Kepemimpinan (leadership).

\section{Metode Analisis Data}

Data hasil observasi dan hasil tes sebelum dan setelah pemberian materi $\mathrm{ACB}$ dianalisis menggunakan pendekatan kualitatif dan kuantitatif. Terhadap data kualitatif, yaitu data yang tidak dalam bentuk angka tapi berupa penjelasan atau keterangan dilakukan analisa dengan menggabungkan informasi lalu diungkapkan sesuai dengan gejala sosial yang terjadi.

Dalam proses analisis data kuantitatif, setiap interpretasi logis atas data akan dilengkapi dengan datadata kuantitatif sepanjang data tersebut dapat mendukung, mempertajam dan memperjelas interpretasi. Analisis kuantitatif dilakukan terhadap data hasil pengisian pre test dan post test oleh siswa. Teknis analisis data kuantitif menggunakan uji statistik dengan bantuan software Excel/SPSS 16.0.

Teknis analisis statistik untuk menguji hipotesis dalam penelitian ini menggunakan uji peringkat-bertanda Wilcoxon untuk hasil pretest dan posttest siswa. Uji ini memanfaatkan tanda plus dan minus yang diperoleh dari selisih antara penilaian sebelum dan setelah pemberian materi ACB. Uji ini memanfaatkan arah (positif atau negatif) dan besarnya arah tersebut (besarnya selisih 


\section{JURNAL TAMBORA}

Vol. 3 No. 1 Februari 2019

antara nilai sebelum dan setelah perlakuan) (Walpole, 1992). Uji ini cocok digunakan untuk menganalisis hasil pengamatan yang berpasangan dari dua data apakah berbeda atau tidak.

\section{HASIL DAN PEMBAHASAN}

\section{Hasil Penelitian}

\section{Pengurusan Ijin Penelitian}

Pengurusan ijin penelitian diperlukan sebagai dasar hukum pelaksanaan penelitian. Pengurusan ijin penelitian dilakukan di Fakultas Psikologi Universitas Teknologi Sumbawa dan SMAN 2 Sumbawa Besar sebagai lokasi penelitian ini.

\section{Pelaksanaan Penelitian}

Pelaksanaan penelitian terdiri dari tiga tahapan: (1)

Pretest; (2) Pemberian materi; dan (3) Posttest.

Kegiatan pretest diikuti oleh 266 peserta dengan hasil sebagai berikut: (1) skor maksimum 60; (2) skor minimum 10; dan (3) skor rata-rata 42.93. Pemberian delapan modul materi ACB dilakukan dengan kombinasi beberapa metode, yaitu instruksi (ceramah), diskusi, simulasi, role playing, dan permainan (game).

Secara umum nilai-nilai karakter positif yang tercakup dalam modul ACB adalah sebagai berikut:

1. Orang yang mengenal baik dirinya cenderung mempunyai konsep diri positif. Kekuatan dan kelemahan diri diketahui dengan baik. Orang yang mengenal baik dirinya akan menjadi pribadi yang matang, percaya diri, tidak takut menghadapi resiko kegagalan, dan siap menghadapi tantangan.

2. Efektifitas proses pembelajaran di sekolah salah satunya ditentukan oleh gaya belajar siswa karena strategi dan metode pembelajaran yang tepat menyebabkan siswa belajar dengan mudah dan menyenangkan. Gaya belajar siswa bermacammacam, ada yang belajar lebih cepat dengan mendengarkan, ada yang lebih cepat dengan membaca, ada yang lebih cepat dengan bereksperimen dan sebagainya.

3. Pribadi yang memiliki tujuan dan misi yang jelas dalam hidupnya disertai manajemen waktu yang baik dapat merengkuh pencapaian terbaik di masa depan. Manajemen waktu merupakan satu-satunya determinasi mewujudkan goal dan misi. Dengan kejelasan tujuan dan misi pribadi, maka waktu dijadwalkan secara definitif. Remaja yang berhasil adalah remaja yang mampu mengelola waktu secara efektif, efisien dan produktif.

4. Pengaruh positif kepribadian proaktif terhadap keberhasilan dalam hidup seseorang terjadi dalam dua cara: pertama, individu yang proaktif memiliki personal control, sense of determination, dan selfefficacy yang besar; kedua, individu proaktif akan memilih dan menciptakan lingkungan sesuai keinginannya.

5. Konflik dapat dikelola dengan baik jika seseorang memiliki keterampilan, sikap dan pengetahuan tentang teknik komunikasi, kemampuan mendengarkan secara aktif dan sikap disiplin. Komunikasi yang baik dan
JURNAL TAMBORA

ISSN 2527-970X | e-ISSN 2621-542X

kemampuan mendengarkan secara aktif akan menciptakan lingkungan yang terapetik dan kondusif. Sikap disiplin meminimalisir potensi konflik karena tingkat kepatuhan dan pengetahuan tentang aturan dan norma yang berlaku di dalam masyarakat, organisasi, keluarga dan sebagainya mencegah potensi konflik dengan pihak lain.

6. Menurut Bloom et al. (1985) dalam Sriyanto et el. (2014), individu yang tingkat asertivitasnya tinggi dapat menjadi pertahanan diri yang efektif dan adaptif, mampu mengenal diri sendiri dengan baik, mengetahui kekurangan dan kelebihan dirinya, sehingga mampu merencanakan tujuan hidupnya, yang mempunyai rasa percaya diri, dan mampu mengambil keputusan.

7. Melalui pembentukan sikap empatik dan menghargai orang lain akan terbangun keterbukaan dan kepercayaan yang mutlak dibutuhkan dalam membangun relasi dengan orang lain. Sikap empati membuat seseorang mampu menyampaikan pesan dengan cara dan sikap yang memudahkan orang lain menerima pesan yang disampaikan. Menghargai orang lain membutuhkan totalitas memahami perasaan, kepedulian dan perhatian terhadap orang yang berbicara. Sikap menghargai orang lain tentu harus timbal balik sebagai prasyarat munculnya saling pemahaman.

8. Kepemimpinan (leadership) berkenaan dengan kemampuan seseorang mempengaruhi orang untuk sebuah tujuan (Yudiatmaja, 2013). Pada hakekatnya kepemimpinan merupakan keterampilan atau kemampuan yang dapat dibangkitkan pada diri setiap orang. Karakter pemimpin dicirikan dari ambisi dan energi, hasrat untuk memimpin, kejujuran dan integritas, percaya diri dan kecerdasan serta pengetahuan. Selain itu karakter pemimpin adalah kemampuan pemantauan diri yang tinggi (luwes menyesuaikan perilaku pada kondisi berbeda).

Di akhir program peserta diberikan posttest untuk mengukur efektivitas pemberian program ACB. Kegiatan ini diikuti oleh 266 peserta dengan hasil sebagai berikut: (1) skor maksimum 80; (2) skor minimum 40; dan (3) skor rata-rata 60.71 .

\section{Pembahasan}

\section{Uji Normalitas}

Uji normalitas dilakukan untuk menentukan apakah data memiliki distribusi normal atau tidak karena hal tersebut akan menentukan analisis yang akan dilakukan. Jika data memiliki distribusi normal, maka dilakukan analisis statistik parametrik. Sedangkan jika data memiliki distribusi tidak normal, data ordinal, atau data skala, maka dilakukan analisis statistik non parametrik.

Berdasarkan hasil uji normalitas, data penelitian memiliki nilai signifikansi kurang dari 0.05 sehingga dikategorikan sebagai data yang tidak memiliki distribusi normal sebagaimana disajikan pada Tabel 1. Selanjutnya dilakukan uji statistik non parametrik yang cocok untuk 


\section{JURNAL TAMBORA}

\section{Vol. 3 No. 1 Februari 2019}

kelompok data berpasangan, yaitu uji peringkat-bertanda Wilcoxon.

Tabel 1. Hasil uji normalitas

Tests of Normality

\begin{tabular}{|c|c|c|c|c|c|}
\hline \multirow{2}{*}{\multicolumn{2}{|c|}{ Kelompok }} & \multicolumn{3}{|c|}{ Kolmogorov-Smirnova } & Shapiro-Wilk \\
\hline & & Statistic & df & Sig. & Statistic df Sig. \\
\hline & Pre_test & .184 & 266 & .000 & .912266 .000 \\
\hline & Post Test & .234 & 266 & .000 & .864266 .000 \\
\hline
\end{tabular}

Lilliefors Significance Correction

\section{Deskripsi Data}

Deskripsi data empirik dan hipotetik disajikan pada Tabel 2. Secara hipotetik skor memiliki rentang nilai 0100 dengan rata-rata 50, simpangan baku 29,30 dan standard of error 2,92. Data hasil pre test menunjukkan skor terendah adalah 10 dan skor tertinggi adalah 40 dengan rata-rata empirik sebesar 42,93, simpangan baku 11,93 dan standard of error 0,73. Data hasil post test menunjukkan skor terendah adalah 40 dan skor tertinggi adalah 80 dengan rata-rata empirik sebesar 60,71, simpangan baku 9,27 dan standard of error 0,57.

Tabel 2. Deskripsi data empirik dan hipotetik hasil skor pre test dan post test

\begin{tabular}{lccc}
\hline \multirow{2}{*}{ Ukuran } & \multicolumn{2}{c}{ Empirik } & \multirow{2}{*}{ Hipotetik } \\
\cline { 2 - 3 } & Pre test & Post test & \\
\hline Skor minimal & 10 & 40 & 0 \\
\hline Skor maksimal & 60 & 80 & 100 \\
\hline Rata-rata & 42,93 & 60,71 & 50 \\
\hline Simpangan baku & 11,93 & 9,27 & 29,30 \\
\hline Standard of & 0,73 & 0,57 &
\end{tabular}

Error

Berdasarkan data Tabel 2 di atas, rata-rata empirik pretest lebih kecil dari rata-rata hipotetik yang menunjukkan bahwa secara umum pemahaman peserta tentang nilai-nilai karakter positif program ACB masih rendah. Sedangkan rata-rata empirik posttest lebih besar dari rata-rata hipotetik yang menunjukkan bahwa secara umum pemahaman peserta tentang nilai-nilai pendidikan karakter program ACB lebih tinggi setelah mereka mendapatkan materi ACB.

Perbandingan nilai simpangan baku menunjukkan bahwa simpangan baku empirik pretest dan posttest lebih rendah dari simpangan baku hipotetik. Hasil perbandingan tersebut menunjukkan bahwa secara umum tingkat pemahaman peserta terhadap materi ACB memiliki variasi yang rendah. Dengan kata lain persepsi antara satu peserta dengan peserta lainnya relatif sama atau seragam.

Nilai standard of error yang diperoleh cukup kecil baik di pretest maupun posttest yang menunjukkan bahwa nilai rata-rata yang diperoleh memiliki simpangan yang kecil. Perbandingan nilai standard of error mengikuti perbandingan nilai simpangan bakunya dimana nilai standard of error pre test lebih tinggi dibandingkan post test.
JURNAL TAMBORA

ISSN 2527-970X | e-ISSN 2621-542X

Selanjutnya dilakukan kategorisasi skor hasil pre test dan post test. Proses kategorisasi mengacu pada pada pendapat Azwar (2012) yang didasarkan pada signifikansi perbedaan, yaitu dengan menguji perbedaan rata-rata skor empirik dengan skor hipotetik (teoritik). Kategorisasi dengan cara ini dilakukan dengan tujuan untuk mengkategorikan individu ke dalam jenjang rendah, sedang dan tinggi, namun tidak dengan mengasumsikan distribusi populasi yang normal, dan dilakukan jika jumlah individu dalam kelompok tidak terlalu besar.

Hasil kategorisasi dan interpretasi skor pretest dan posttest disajikan pada Tabel 3, Tabel 4 dan Gambar 1 . Hasil kategorisasi dan interpretasi skor pretest menunjukkan bahwa 145 peserta atau $54,51 \%$ dari total peserta program ACB memiliki pemahaman tentang nilainilai karakter positif program ACB kategori sedang, 67 peserta atau $25,19 \%$ dari total peserta memiliki pemahaman kategori rendah dan 54 peserta atau 20,30\% dari total peserta memiliki pemahaman kategori tinggi.

Tabel 3. Kategorisasi dan interpretasi skor pretest

\begin{tabular}{lccc}
\hline Kategori & Skor & Frekuensi & $\begin{array}{c}\text { Persentase } \\
(\mathbf{\%})\end{array}$ \\
\hline Tinggi & $\geq 55$ & 54 & 20,30 \\
\hline Sedang & $\begin{array}{c}31<\mathrm{x} \\
55\end{array}$ & 145 & 54,51 \\
\hline Rendah & $<31$ & 67 & 25,19 \\
\hline \multicolumn{2}{c}{ Jumlah } & $\mathbf{2 6 6}$ & $\mathbf{1 0 0}$ \\
\hline
\end{tabular}

Tabel 4. Kategorisasi dan interpretasi skor posttest

\begin{tabular}{lccc} 
Kategori & Skor & Frekuensi & $\begin{array}{c}\text { Persentase } \\
(\mathbf{\%})\end{array}$ \\
\hline Tinggi & $\geq 70$ & 79 & 29,70 \\
\hline Sedang & $\begin{array}{c}51<\mathrm{x} \\
70\end{array}$ & 106 & 39,85 \\
\hline Rendah & $<51$ & 81 & 30,45 \\
\hline \multicolumn{2}{c}{ Jumlah } & $\mathbf{2 6 6}$ & $\mathbf{1 0 0}$ \\
\hline \multicolumn{2}{r}{}
\end{tabular}

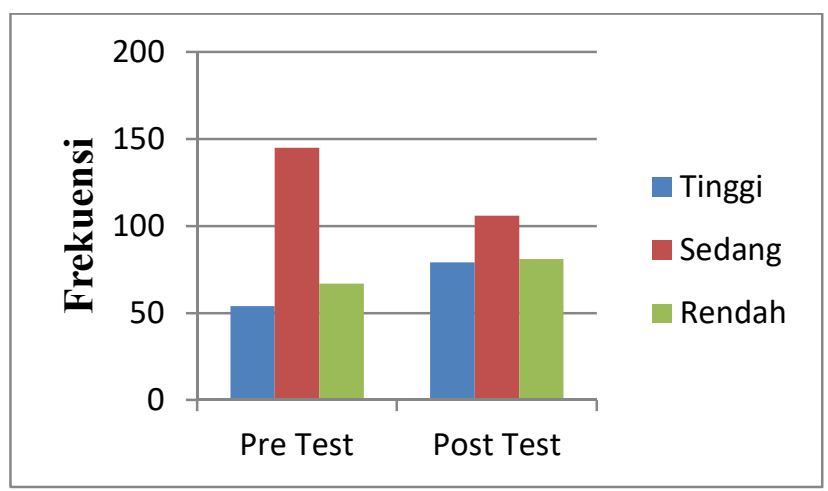

Gambar 1. Kategorisasi skor pretest dan posttest

\section{Uji Peringkat-Bertanda Wilcoxon}

Uji peringkat-bertanda Wilcoxon digunakan untuk mengetahui ada tidaknya perbedaan rata-rata dua sampel yang berpasangan (pretest dan posttest) terhadap data yang tidak berdistribusi normal. Berdasarkan hasil uji peringkat-bertanda Wilcoxon, nilai signifikansi 0.00 atau 


\section{JURNAL TAMBORA}

Vol. 3 No. 1 Februari 2019

lebih kecil dari 0.05 sehingga dapat disimpulkan bahwa ada perbedaan antara hasil pretest dan posttest. Dengan kata lain ada pengaruh pemberian program ACB terhadap penanaman karakter peserta program. Hasil uji peringkatbertanda Wilcoxon disajikan pada Tabel 5 dan Tabel 6 .

Tabel 5. Hasil uji peringkat-bertanda Wilcoxon

\begin{tabular}{lr}
\multicolumn{3}{c}{ Test Statistics $^{b}$} \\
\hline \multicolumn{3}{c}{ Post Test - Pre Test } \\
\hline $\mathrm{Z}$ & $-12.377^{\mathrm{a}}$ \\
\hline Asymp. Sig. (2-tailed) & .000 \\
\hline a. Based on negative ranks. \\
b. Wilcoxon Signed Ranks Test
\end{tabular}

Tabel 6. Sebaran hasil perangkinan skor tes

\begin{tabular}{|c|c|c|c|c|}
\hline \multicolumn{5}{|c|}{ Ranks } \\
\hline & & $\mathrm{N}$ & $\begin{array}{c}\text { Mean } \\
\text { Rank }\end{array}$ & $\begin{array}{c}\text { Sum of } \\
\text { Ranks }\end{array}$ \\
\hline \multirow{4}{*}{$\begin{array}{c}\text { Post Test - } \\
\text { Pre Test }\end{array}$} & Negative Ranks & $18^{\mathrm{a}}$ & 38.50 & 693.00 \\
\hline & Positive Ranks & $206^{b}$ & 118.97 & 24507.00 \\
\hline & Ties & $42^{c}$ & & \\
\hline & Total & 266 & & \\
\hline
\end{tabular}

a. Post Test < Pre Test; b. Post Test > Pre Test; c. Post Test $=$ Pre Test

Negative Ranks atau selisih skor pretest dan posttest yang negatif sebanyak 18 yang berarti bahwa terdapat 18 peserta yang skor posttest-nya lebih kecil dibandingkan skor pretest dengan rata-rata skor 38,50. Positive Ranks atau selisih skor pretest dan posttest yang positif sebanyak 206 yang berarti bahwa terdapat 206 peserta yang skor posttest-nya lebih tinggi dibandingkan skor pretest dengan rata-rata skor 118,87 . Ties adalah tidak adanya perbedaan antara skor pretest dan posttest sebanyak 42 yang berarti bahwa terdapat 42 peserta yang memiliki skor pretest sama dengan posttest. Total peserta adalah 266 orang.

Efektifnya intervensi program ACB pada penelitian ini kemungkinan disebabkan oleh faktor internal dan faktor eksternal. Faktor internal meliputi telah adanya pemahaman sebagian peserta tentang nilai-nilai pendidikan karakter yang harus dimiliki remaja. Hal ini terlihat dari cukup tingginya skor pre test peserta yang mencapai angka maksimum 60. Faktor eksternal meliputi metode, materi dan pemberi materi ACB. Metode pembelajaran yang digunakan cukup komprehensif yaitu instruksi (ceramah), diskusi, simulasi, role playing dan permainan (game). Materi yang tercakup dalam modulmadul program ACB cukup relevan dengan permasalahan yang dihadapi saat ini. Pemberi materi merupakan psikolog dan co-assisstant yang cukup profesional.
JURNAL TAMBORA

ISSN 2527-970X | e-ISSN 2621-542X

\section{PENUTUP}

\section{Kesimpulan}

Beberapa kesimpulan dari penelitian ini adalah:

1. Program ACB dapat menginternalisasi nilai-nilai dan pendidikan karakter pada peserta atau siswa.

2. Hasil penelitian menunjukkan skor rata-rata peserta sebelum pemberian program 42.9 dan skor rata-rata peserta 60.71 setelah pemberian program.

3. Peningkatan tersebut terutama disebabkan faktor internal dan eksternal. Faktor internal berupa adanya pemahaman sebagian peserta tentang nilai dan pendidikan karakter. Faktor eksternal berupa metode dan kapasitas pemberi materi yang tepat, profesional dan menyenangkan.

\section{Saran}

Beberapa saran dalam rangka penyempurnaan penelitian di masa mendatang adalah:

1. Alokasi waktu yang lebih banyak agar penyampaian materi lebih terinternalisasi kepada peserta.

2. Dukungan fasilitas pelaksanaan program di sekolah yang lebih representatif, seperti kenyamanan ruangan, sarana pendukung belajar.

3. Perlu dilakukan penyempurnaan modul ACB berdasarkan hasil evaluasi pelaksanaan program.

\section{REFERENSI}

Azwar, S. 2012. Penyusunan Skala Psikologi. Pustaka Pelajar. Yogyakarta.

Herlina. 2013. Bibliotherapy: Mengatasi Masalah Anak dan Remaja melalui Buku. Pustaka Cendekia Utama. Bandung.

Oswalt, A. 2010. An Introduction to Adolescent Development. http://www.mentalhelp.net/poc/ view_doc.php?type $=$ doc\&id $=41149 \& \mathrm{cn}=1310$ (Diakses tanggal 24 Maret 2017.

Sriyanto, A. Abdul Karim, A. Zainul, E. Maryani. 2014. Perilaku Asertif dan Kecenderungan Kenakalan Remaja Berdasarkan Pola Asuh dan Peran Media Massa. Jurnal Psikologi Vol 41 No 1, Juni 2014. Universitas Pendidikan Indonesia. Bandung.

Sugiyono. 2012. Metode Penelitian Kuantitatif, Kualitatif dan R\&D. Penerbit Alfabeta. Bandung.

Suryana. 2010. Metodologi Penelitian: Model Praktis Penelitian Kuantitatif dan Kualitatif. Universitas Pendidikan Indonesia. Bandung.

Walpole, R. E. 1992. Pengantar Statistika. PT Gramedia Pustaka Utama. Jakarta.

Yudiaatmaja, F. 2013. Kepemimpinan: Konsep, Teori dan Karakternya. Media Komunikasi FIS Volme 12, Nomor 2 tanggal 2 Agustus 2013. https://ejournal.undiksha.ac.id/index.php/MKFIS/art icle/download/1681/1469 (Diakses tanggal 14 September 2017). 